\title{
Modelling of real area of contact between tool and workpiece in metal forming processes including the influence of subsurface deformation
}

\author{
Nielsen, Chris Valentin; Martins, Paulo A. F.; Bay, Niels Oluf
}

Published in:

CIRP Annals : Manufacturing Technology

Link to article, DOI:

10.1016/j.cirp.2016.04.126

Publication date:

2016

Document Version

Peer reviewed version

Link back to DTU Orbit

Citation (APA):

Nielsen, C. V., Martins, P. A. F., \& Bay, N. O. (2016). Modelling of real area of contact between tool and workpiece in metal forming processes including the influence of subsurface deformation. CIRP Annals : Manufacturing Technology, 65, 261-264. https://doi.org/10.1016/j.cirp.2016.04.126

\section{General rights}

Copyright and moral rights for the publications made accessible in the public portal are retained by the authors and/or other copyright owners and it is a condition of accessing publications that users recognise and abide by the legal requirements associated with these rights.

- Users may download and print one copy of any publication from the public portal for the purpose of private study or research.

- You may not further distribute the material or use it for any profit-making activity or commercial gain

- You may freely distribute the URL identifying the publication in the public portal 


\title{
Modelling of real area of contact between tool and workpiece in metal forming processes including the influence of subsurface deformation
}

\author{
Chris V. Nielsen ${ }^{1}$, Paulo A.F. Martins ${ }^{2}$ and Niels Bay ${ }^{1}$ \\ ${ }^{1}$ Department of Mechanical Engineering, Technical University of Denmark, 2800 Kgs. Lyngby, Denmark \\ ${ }^{2}$ IDMEC, Instituto Superior Tecnico, Universidade de Lisboa, Portugal, 1049-001 Lisbon, Portugal
}

\begin{abstract}
New equipment for testing asperity deformation at various normal loads and subsurface elongations is presented. Resulting real contact area ratios increase heavily with increasing subsurface expansion due to lowered yield pressure on the asperities when imposing subsurface normal stress parallel to the surface. Finite element modelling supports the presentation and contributes by extrapolation of results to complete the mapping of contact area as function of normal pressure and one-directional subsurface strain parallel to the surface. Improved modelling of the real contact area is the basis for estimating friction in the numerical modelling of metal forming processes.
\end{abstract}

\section{Keywords}

Metal forming, Friction, Real contact area

\section{Introduction}

Among mechanisms in frictional sliding in metal forming, Bowden and Tabor [1] identified shearing of layers due to adhesion and cold welding between two surfaces and dragging or ploughing of a harder material through a softer material. Wanheim and Abildgaard [2] later added plastic waves in the softer material as an additional mechanism.

Bowden and Tabor [1] described the influence of asperity contact on friction, and observed that the linearity between normal pressure and friction in Amontons-Coulomb's model disappears when the real contact area becomes large. This was solved by Orowan [3] in modelling of rolling by applying the shear flow stress as an upper limit, and refined by the suggestion of a smooth transition by Shaw et al. [4].

Another important remark by Bowden and Tabor [1] is that friction cannot be regarded as a pure surface effect. Plastic bulk deformation influences the formation of contact area and hence friction. Fogg [5] observed during stretch forming, where subsurface deformation is present, that the real area of contact increases with bulk deformation due to the reduction of yield pressure when overlaid by tensile stresses.

The real area of contact, which explains the smooth transition suggested by Shaw et al. [4], has been investigated by slip-line analysis by Wanheim and Bay [6], who determined real area of contact as function of normal pressure by assuming regular asperities in contact with a smooth rigid tool under plane strain deformation. Wilson and Sheu [7] used upper bound analysis to set up a model for longitudinal asperities in rolling.

The mentioned theoretical models assume no subsurface deformation, and miss therefore one of the mechanisms influencing the formation of real contact area. Sutcliffe [8] developed a slip-line field, by combination of the field for equidistant indenters and the field for uniform deformation, for the analysis of real contact area as function of both normal pressure and subsurface deformation.

While Sutcliffe [8] was able to include subsurface deformation in his slip-line analysis, he was not able to include asperity interaction upon deformation as Wanheim and Bay [6] did, and on the contrary, they were not able to handle subsurface deformation. As far as the authors are aware, there is still no existence of a slip-line field that can handle both. Another limitation of slip-line analysis is the absence of strain hardening, although Bay [9] extended the analysis by including strain hardening in an average sense, and Sutcliffe [8] also gave an estimate of the effect of strain hardening.

These limitations call for the advantages of numerical analysis, although they cannot give direct analytical expressions. Makinouchi et al. [10] analysed three asperities with free sides by elasto-plastic finite element analysis, where it was possible to include strain hardening. Later, the model was extended by Ike and Makinouchi [11] to five asperities and also single asperities with periodic boundary conditions. They were able to analyse different levels of subsurface deformation with their models. Another study was made by Korzekwa et al. [12], who simulated asperity deformation under different straining directions. They included strain hardening in an average sense. Lately, Wang et al. [13] derived a friction model based on a five-asperity model, where bulk deformation was also included.

Nielsen et al. [14] focused on the influence of strain hardening of the workpiece material for various normal pressures and presented an analytical expression for the real contact area as function of normal pressure and the strain hardening exponent. This study was performed without subsurface deformation, and this is what the present paper adds to these previous simulations.

The aim of the present paper is to show the real contact area ratio as function of subsurface deformation and normal pressure for a strain hardening material in terms of experiments and numerical simulations. The analysis covers compressive as well as tensile subsurface deformation, thereby covering the complete range of predominant stress distributions in metal forming processes, where friction modelling is required.

\section{Experimental setup}

Flattening of model asperities is conducted under different levels of normal pressure $q$ and subsurface longitudinal strain $\varepsilon_{l}$. Figure 1 shows two types of test specimens that are used. The bone shaped specimen in Figure 1a is designed for longitudinal tension, while the specimen in Figure 1b is designed for longitudinal compression. Both specimens have regular, two-dimensional model asperities perpendicular to the direction of subsurface deformation made by wire-cut EDM. They have triangular cross-section and are scaled up in size to allow clear detection of the real contact area ratio, and they are modelled by a flank angle $\gamma=10^{\circ}$ and a wavelength $t=1.5 \mathrm{~mm}$. 


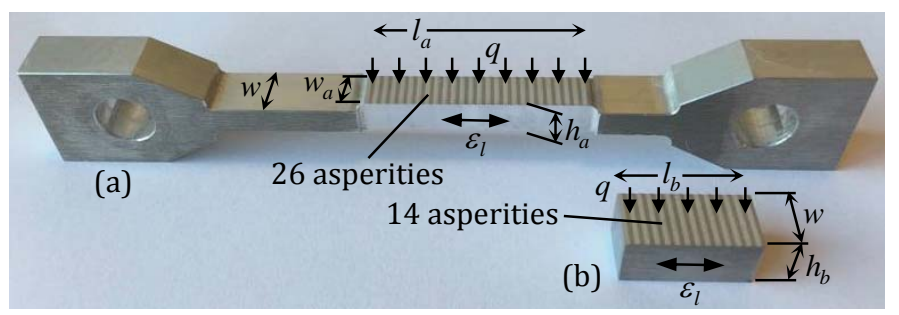

Figure 1. Test specimens with model asperities to be flattened under normal pressure $q$ while experiencing subsurface longitudinal strain $\varepsilon_{l}$ due to (a) longitudinal tension or (b) longitudinal compression. Dimensions are $w=10 \mathrm{~mm}, w_{a}=7 \mathrm{~mm}, l_{a}=39 \mathrm{~mm}, l_{b}=21 \mathrm{~mm}, h_{a}=10 \mathrm{~mm}$ and $h_{b}=9.5 \mathrm{~mm}$.

The workpiece material is aluminium A1050 with a Hollomon flow stress curve,

$$
\sigma=C \varepsilon^{n}=140 \varepsilon^{0.21}[\mathrm{MPa}]
$$

obtained by simple upsetting tests. In Eq. (1), $C$ is the strength coefficient and $n$ is the strain hardening exponent. In the asperity flattening experiments, fine zinc stearate powder was used for lubrication. It was rubbed to the workpiece surface after pickling in a $\mathrm{NaOH}$ bath. The zinc stearate was applied in a thin layer to minimize the possibility of entrapment in the valleys during asperity flattening, which would diminish the formation of real contact between workpiece and tool.

The experiments were conducted in a channel tool installed for asperity flattening under tensile subsurface deformation as shown in Figure 2 or compressive subsurface deformation as shown in Figure 3.

The testing procedure in the experiments shown in Figure 2 is:

- The test specimen (1) is placed in the channel tool (2) for aligning purposes and for support on the bottom.

- The punch (3) moves down to apply a normal force on the asperities. The force is kept constant throughout the test and the final normal pressure $q$ is calculated based on the final dimensions of the test specimen.

- Longitudinal subsurface strain is induced by tension through the position controlled axis (4), while the other end of the specimen is clamped by the shoe (5) and the chock preventing movement of this end (6).

- Steady state sliding is obtained by removing the chock (6), which allows free movement of the specimen including the clamping shoe (5) to the left by the position controlled axis (4).

The testing procedure in the experiments with compressive subsurface deformation as in Figure 3 is:

- The test specimen (7) is placed in the channel tool (8) to ensure plane strain deformation.

- The stationary tool (10) impedes movement in one direction while movement to the opposite end is initially hindered by having the position controlled counter pressure tool (11) in contact with the specimen.

- The punch (9) moves down to apply a normal pressure $q$ on the workpiece asperities.

- The position controlled tool (11) is moved a certain distance to allow subsurface deformation of the specimen. This deformation happens under longitudinal compression as the workpiece is deformed against tool (11).

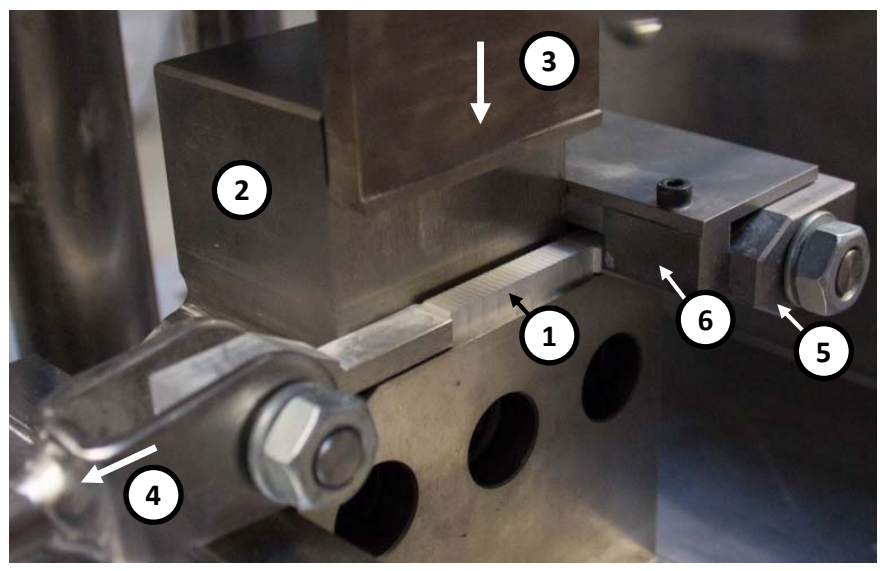

Figure 2. Experimental setup for asperity flattening under tensile subsurface deformation showing (1) test specimen, (2) channel tool consisting of a bottom and two sides (of which one was removed for taking the photograph), (3) punch, (4) position controlled axis, (5) clamping shoe, and (6) removable chock. 


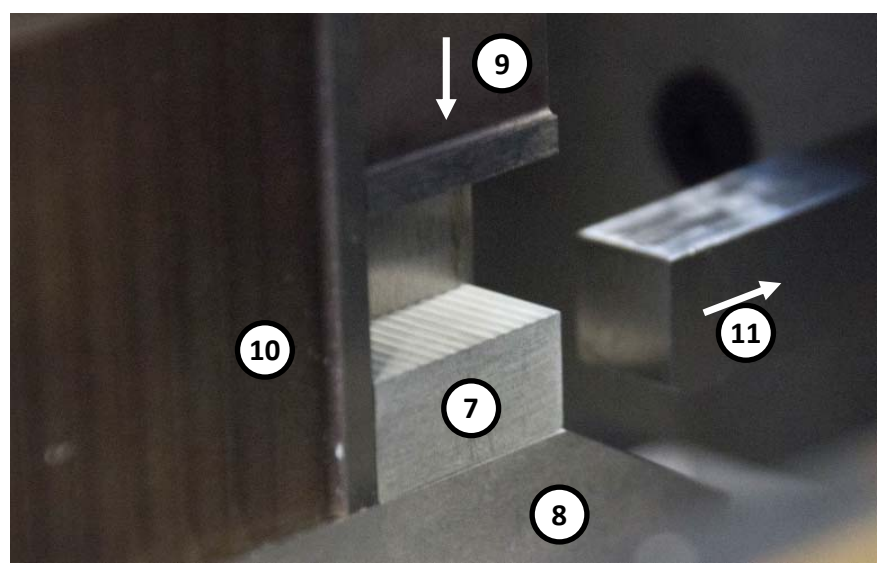

Figure 3. Experimental setup for asperity flattening under compressive subsurface deformation showing (7) test specimen, (8) channel tool consisting of a bottom and two sides (of which one was removed for taking the photograph), (9) punch, (10) stationary tool, and (11) position controlled counter pressure tool.

Plane strain deformation is ensured by the channel tool in Figure 3. This is not the case in the experiments shown in Figure 2, since, if the specimen has the width of the channel tool and is expanded towards the sides, friction will hinder the elongation of the asperity region, and the result will instead be necking in front of the test zone. To avoid necking, the asperity region is made narrower than the channel tool as it can be seen in Figure 1a $\left(w_{a}<w\right)$. In absence of friction between the specimen and the bottom tool (part of the channel tool (2)) and the punch (3), this would result in a plane stress state. Presence of friction does however alter the stress state from pure plane stress. In some cases, as it will be discussed in Section 4, the resulting width of the asperity region does not deviate much from the original width due to friction and the competition between widening due to compression (by the punch (3)) and thinning due to elongation (by axis (4)).

The resulting real contact area ratios were in both setups determined subsequently by 2D scanning of the asperity surface of the test specimens, followed by line identification of the edges separating contact and non-contact. Simple pixel counting was hereafter applied in calculation of the real contact area ratio.

\section{Numerical model}

The two cases are simulated numerically by two-dimensional finite element analysis. The initial meshes consisting of bilinear quadrilateral elements with eight velocity degrees of freedom (two per node) are shown in Figures 4 and 5 for the tensile and compressive subsurface deformation, respectively. In both cases, the asperities are discretized by 64 elements per wavelength along the surface. The underlying finite element calculations are built upon the irreducible flow formulation with theoretical details and numerical implementation described elsewhere [15]. The simulations of the former case (Figure 4) is performed in both plane stress and plane strain to support the analysis due to the abovementioned specimen geometry, while the latter case (Figure 5) is simulated in plane strain only in accordance with the experiment.

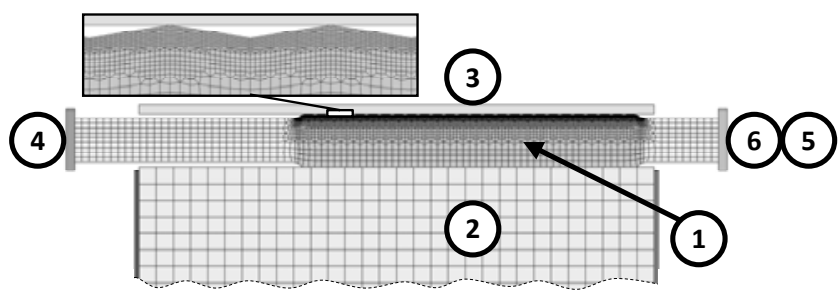

Figure 4. Finite element model for simulation of asperity flattening under tensile subsurface deformation. Numbers in circles correspond to the identification in Figure 2.

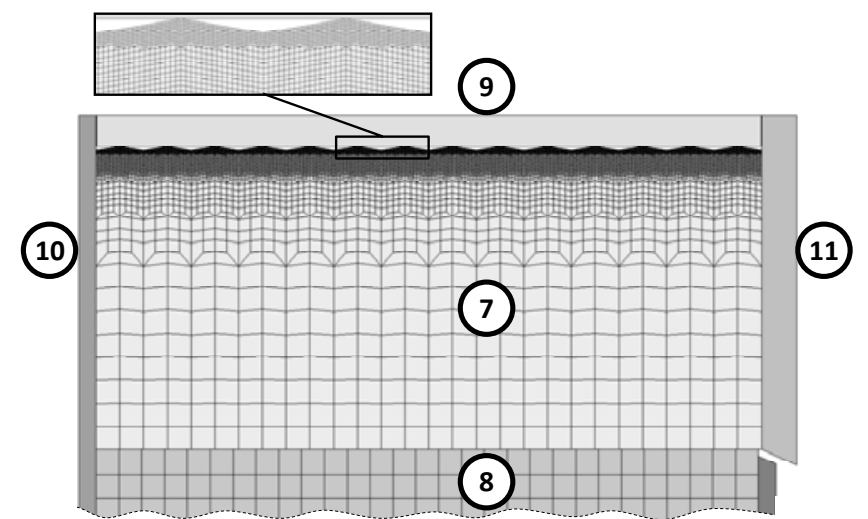

Figure 5. Finite element model for simulation of asperity flattening under compressive subsurface deformation. Numbers in circles correspond to the identification in Figure 3. 
The applied normal force is applied as a pressure boundary condition on the discretized bottom tools (identified as (2) and (8) in the two figures), while the punches (identified as (3) and (9)) are rigid tools, where constant friction is assumed with friction factor 0.3, which is a typical value for soap lubricated aluminium [16]. After reaching the specified normal load, the tensile elongation is simulated by moving tool (4) in Figure 4, while tool (6) is stationary. The subsequent sliding is obtained by additional movement of tool (4) while ignoring clamping of the other end of the workpiece by tool (6). A simulated sliding length of $s=10 \mathrm{~mm}$ results in a normalized sliding length $s / t=6.7$, which is in steady state sliding for the mentioned friction factor [16]. After reaching the specified normal load in Figure 5, tool (11) is moved in order to allow bulk deformation of the specimen (7) under longitudinal compression.

\section{Results and discussion}

The two presented setups, both experimental and numerical, allow the investigation of a large range of normal pressures and subsurface strains. At large normal pressures, the longitudinal compression makes small strains possible, while at low normal pressures, the longitudinal tension enables larger strains. Based on the flow stress curve in Eq. (1) and von Mises yield criterion, the normal pressure needed for yielding in absence of longitudinal loading is given by,

$$
\left(\frac{q}{C}\right)_{\text {yield }}=\frac{2 \varepsilon_{l}^{n}}{\sqrt{3}}\left(\frac{4}{3}\right)^{n / 2}=1.19 \varepsilon_{l}^{0.21}
$$

where $q$ is the nominal normal pressure acting on the apparent area of contact and $\varepsilon_{l}$ is the longitudinal strain, while $C$ and $n$ are the strength coefficient and strain hardening exponent, respectively, in Eq. (1). Eq. (2) is strain dependent due to strain hardening. For ideal plastic materials, the yield normal pressure in absence of longitudinal loading would reduce to $(q / 2 k)_{\text {yield }}=1, k$ being the shear flow stress. Eq. (2) has been used as a guideline for the selection of normal pressures over the selected strain range in the two types of experiments. Normal pressures larger than in Eq. (2) are needed when longitudinal compression is applied, while lower normal pressures are needed when longitudinal tension is applied.

The resulting ratio between real and apparent contact area between tool and workpiece, $\alpha$, is shown in Figures 6 and 7 as function of longitudinal strain under longitudinal tension and compression, respectively.

Simulations in Figure 6 include both plane strain and plane stress, which is expected to encapsulate the experimental results. At low normal pressure, the experiments are generally closer to the plane stress simulations, while they follow the plane strain simulations at larger normal pressure. This is explained by the fact that the specimens are overall loaded in plane stress, but at larger normal pressure, the asperity deformation is close to plane strain due to the increased contact area and resulting friction along the asperities (in the direction of $w_{a}$ in Figure 1a).

In all three cases presented in Figure 6, there is a clear increase in real contact area with increasing subsurface strain, and the amount of area increase seems to be well captured by the numerical model. Both simulations and experiments were carried out under constant force, which results in a decreasing normal pressure with increasing strain. Normal pressures in Figure 6 refer to the nominal normal pressure at $\varepsilon_{l}=0$. Dashed lines correspond to simulated steady state sliding, which is seen not to alter the resulting real contact area as function of subsurface strain.

Figure 7 includes the experimental results for large normal pressures and compressive longitudinal elongation together with the corresponding simulations. Also in this case the increase of contact area with increasing subsurface strain is clear in both experiments and numerical simulations. The experiments and simulations match poorer than in Figure 6, especially at the highest normal pressure. One reason is that workpiece material was extruded up between the punch (9) and the stationary tool (10), referring to Figure 3. This was visible as a flash on the test specimen (7) after the test. This extrusion will lower the effective normal pressure on the asperity surface, and hence the measured real area of contact will correspond to lower normal pressures than given by the measured punch force and specimen area as observed by Nellemann et al. [17]. Another reason may be entrapment of lubricant at large contact area [17], since it cannot escape to the sides as in the previous case.

Numerically simulated real contact area ratios under plane strain deformation are presented in Figure 8 over a large range of normal pressures from zero subsurface deformation, $\varepsilon_{l}=0$, to longitudinal subsurface strains around $\varepsilon_{l}=0.12$. In contrary to the simulations in Figure 6 , all points in Figure 8 are simulated at constant pressure (by scaling up the force due to elongation of the specimen). Figure 9 shows examples of simulated asperity deformation and effective strain distribution. 


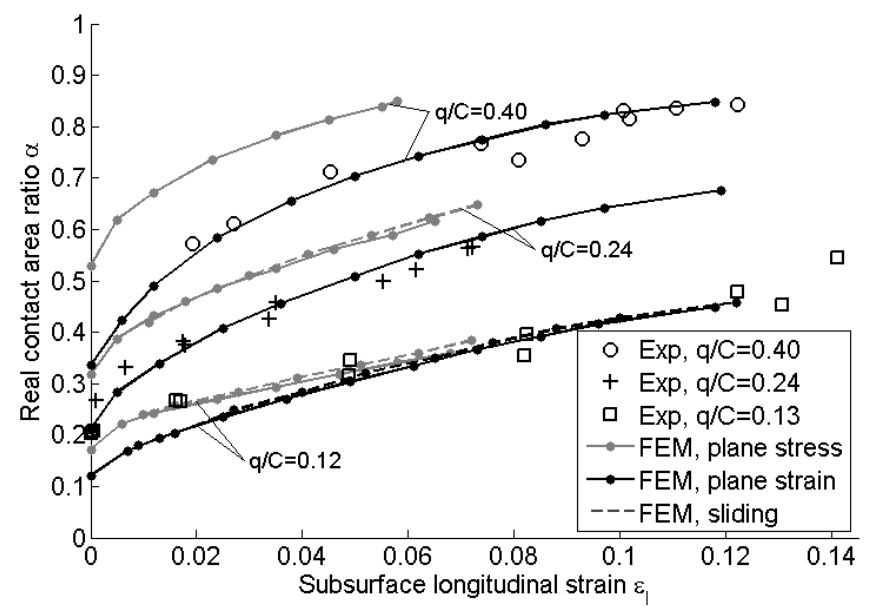

Figure 6. Real contact area ratio as function of subsurface longitudinal strain for different normal pressures obtained by experiments and numerical simulations corresponding to Figures 2 and 4.

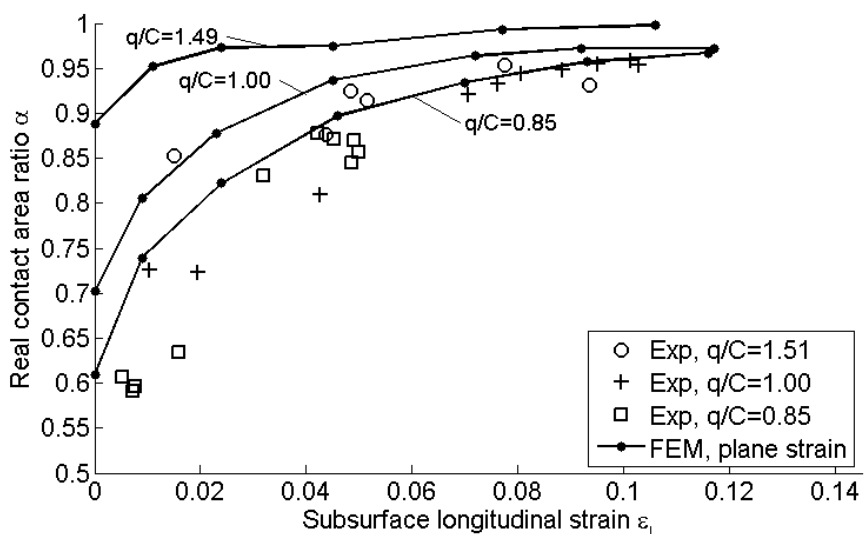

Figure 7. Real contact area ratio as function of subsurface longitudinal strain for different normal pressures obtained by experiments and numerical simulations corresponding to Figures 3 and 5.

The real contact area ratio $\alpha$ is necessary in calculation of the frictional stress $\tau$ on a workpiece surface of instantaneous shear flow stress $k$ with friction factor $f$ by the friction model $\tau=f \alpha k$ proposed by Wanheim and Bay [6]. It is important to notice that Figure 8 is valid for material following the Hollomon expression with a strain hardening exponent $n=0.21$ and for workpiece surfaces that can be represented by a flank angle $\gamma=10^{\circ}$. The real contact area ratio will increase more rapidly for materials with larger strain hardening exponent and for surfaces represented by smaller flank angles.

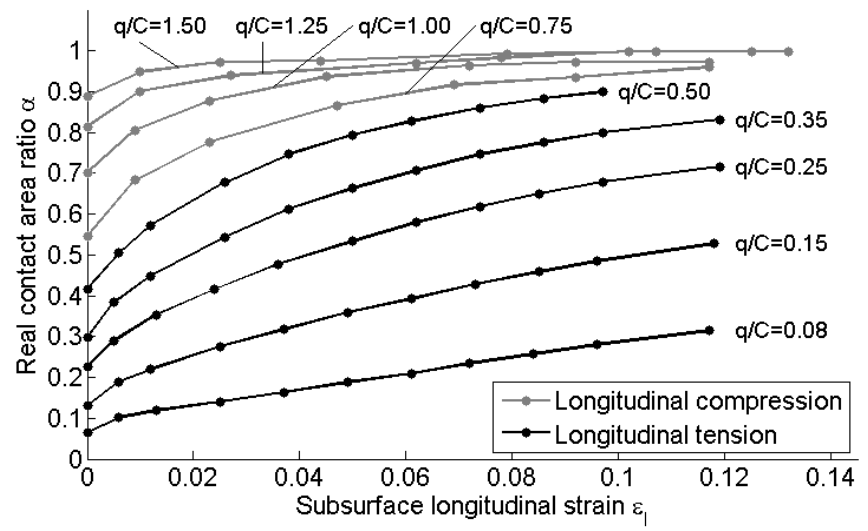

Figure 8. Simulated map of real contact are ratio as function of subsurface longitudinal strain at various normal pressures. The legend identifies simulation by each of the two models in Section 3. 

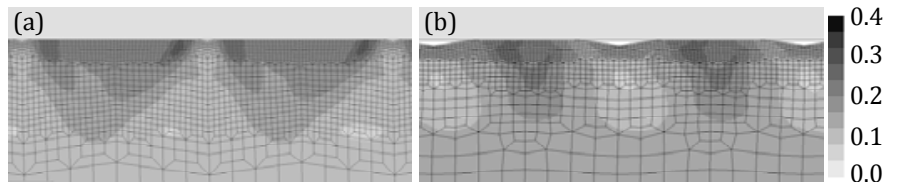

Figure 9. Simulated asperity deformation and effective strain distribution for longitudinal (a) compression with $q / C=1.00$ giving $\varepsilon_{l}=0.023$ and $\alpha=0.88$ and (b) tension with $q / C=0.25$ giving $\varepsilon_{l}=0.62$ and $\alpha=0.58$.

\section{Summary}

Experiments and numerical simulations involving asperity flattening under subsurface longitudinal straining have been presented. Rapid increase of real contact area is observed with increasing strain. The slope will be even steeper in case of larger strain hardening or smaller flank angle. The present work is a step towards full mapping of the real contact area as function of longitudinal strain, strain hardening and flank angles and thereby a step towards an advanced friction model for metal forming. The present paper treats plane strain and plane stress conditions, and can within the same framework be extended to three-dimensional states of deformation and asperity shapes.

\section{Acknowledgements}

The authors would like to thank Mr. A. Ferfecki for experimental work and The Danish Council for Independent Research (Grant number: DFF-1335-00230) for financial support. Paulo Martins would additionaly like to thank Fundação para a Ciência e a Tecnologia de Portugal and IDMEC under LAETA - UID/EMS/50022/2013 and PDTC/EMS-TEC/0626/2014.

\section{References}

[1] Bowden, F.P., Tabor, D., 1942, Mechanism of metallic friction, Nature, 50/3798:197-199.

[2] Wanheim, T., Abildgaard, T., 1980, A mechanism for metallic friction, Proceedings of the 4th International Conference on Production Engineering, Tokyo 122-127.

[3] Orowan, E., 1943, The calculation of roll pressure in hot and cold flat rolling, Proceedings of the Institution of Mechanical Engineers, 150/1:140-167.

[4] Shaw, M.C., Ber, A., Mamin, P.A., 1960, Friction characteristics of sliding surfaces undergoing subsurface plastic flow, Journal of Basic Engineering 342-346.

[5] Fogg, B., 1967-1968, Preliminary study of the influence of stress and deformation in the substrate on junction growth and friction, Proceedings of the Institution of Mechanical Engineers, 182/Pt/3K:152-161.

[6] Wanheim, T., Bay, N., 1978, A model for friction in metal forming processes, Annals of the CIRP, 27:189-194.

[7] Wilson, W.R.D., Sheu, S., 1988, Real area of contact and boundary friction in metal forming, International Journal of Mechanical Sciences, 30/7:475-489.

[8] Sutcliffe, M.P.F., 1988, Surface asperity deformation in metal forming processes, International Journal of Mechanical Sciences, 30/11:847868.

[9] Bay, N., 1984, Tool/workpiece interface stresses in cold forward extrusion, Advanced Technology of Plasticity 1:259-266.

[10] Makinouchi, A., Ike, H., Murakawa, M., Koga, N., 1988, A finite element analysis of flattening of surface asperities by perfectly lubricated rigid dies in metal working processes, Wear, 128:109-122.

[11] Ike, H., Makinouchi, A., 1990, Effect of lateral tension and compression on plane strain flattening processes of surface asperities lying over a plastically deformable bulk, Wear, 140:17-38.

[12] Korzekwa, D.A., Dawson, P.R., Wilson, W.R.D., 1992, Surface asperity deformation during sheet forming, International Journal of Mechanical Sciences, 34/7:521-539.

[13] Wang, Z.G., Yoshikawa, Y., Suzuki, T., Osakada, K., 2014, Determination of friction law in dry metal forming with DLC coated tool, CIRP Annals - Manufacturing Technology, 63:277-280.

[14] Nielsen, C.V., Martins, P.A.F., Bay, N., 2016, General Friction Model Extended by the Effect of Strain Hardening, Proceedings of the $7^{\text {th }}$ International Conference on Tribology in Manufacturing Processes, Phuket 35-44.

[15] Nielsen, C.V., Zhang, W., Alves, L.M., Bay, N., Martins P.A.F., 2013, Modeling of Thermo-Electro-Mechanical Manufacturing Processes with Applications in Metal Forming and Resistance Welding. Springer-Verlag, London.

[16] Bay, N., Wanheim, T., 1976, Real area of contact and friction stress at high pressure sliding contact, Wear, 38:201-209.

[17] Nellemann, T., Bay, N. Wanheim, T., 1977, Real area of contact and friction stress - the role of trapped lubricant. Wear 43:45-53. 